\title{
Operational Lessons Learned from the Ares I-X Flight Test
}

\author{
Stephan R. Davis, Deputy Mission Manager \\ Ares I-X Mission Management Office \\ Marshall Space Flight Center \\ Huntsville, $A L 35812$
}

\begin{abstract}
The Ares I-X flight test, launched in 2009, is the first test of the Ares I crew launch vehicle. This development flight test evaluated the flight dynamics, roll control, and separation events, but also provided early insights into logistical, stacking, launch, and recovery operations for Ares I.

Operational lessons will be especially important for NASA as the agency makes the transition from the Space Shuttle to the Constellation Program, which is designed to be less labor-intensive. The mission team itself comprised only 700 individuals over the life of the project compared to the thousands involved in Shuttle and Apollo missions; while missions to and beyond low-Earth orbit obviously will require additional personnel, this "lean" approach will serve as a model for future Constellation missions.

To prepare for Ares I-X, vehicle stacking and launch infrastructure had to be modified at Kennedy Space Center's Vehicle Assembly Building (VAB) as well as Launch Complex (LC) 39B. In the VAB, several platforms and other structures designed for the Shuttle's configuration had to be removed to accommodate the in-line, much taller Ares I-X. Vehicle preparation activities resulted in delays, but also in lessons learned for ground operations personnel, including hardware deliveries, cable routing, transferred work and custodial paperwork. Ares I-X also proved to be a resource challenge, as individuals and ground service equipment (GSE) supporting the mission also were required for Shuttle or Atlas V operations at LC 40/41 at Cape Canaveral Air Force Station.

At LC 39B, several Shuttle-specific access arms were removed and others were added to accommodate the in-line Ares vehicle. Ground command, control, and communication (GC3) hardware was incorporated into the Mobile Launcher Platform (MLP). The lightning protection system at LC 39B was replaced by a trio of 600 -foot-tall towers connected by a catenary wire to account for the much greater height of the vehicle. Like Shuttle, Ares I-X will be stacked on a MLP and rolled out to the pad on a Saturn-era crawler-transporter. While Ares I-X was only held in place by the four hold-down posts on its aft skirt during rollout, a new vehicle stabilization system (VSS) attached to the vertical service structure kept the vehicle from undue swaying prior to launch at the pad, LC 39B.

Following the launch, the flight test vehicle first stage was recovered with the aid of new parachutes resized to accommodate the five-segment-long first stage, which had a much greater length and mass than the Shuttle's reusable solid rocket boosters. After splashdown, recovery divers exercised extra care when handling the first stage to ensure that the flight data recorders in the fifth segment simulator were not damaged by exposure to sea water. The data recovered from the Ares I-X flight test will be very valuable in verifying the predicted environments and models used to design the vehicle.

Lessons learned from Ares I-X will be shared with the Ares Projects through written and verbal reports and through integration of mission team members into the Project workforce.
\end{abstract}

\section{Introduction}

Since 2005, NASA's Constellation Program has been designing, building, and testing the next generation of launch and space vehicles to carry humans beyond low-Earth orbit (LEO), including the Ares I crew launch vehicle and Ares V cargo launch vehicle. Ares I and Ares V are being managed by the Ares Projects out of NASA's Marshall Space Flight Center (MSFC) in Huntsville, AL. 
Ares I is designed to carry up to four astronauts to the International Space Station (ISS). It also can be launched in tandem with the Ares V cargo launch vehicle to perform a variety of missions beyond LEO. The Ares I-X development flight test was conceived in 2006 to acquire early engineering, operations, and environment data during liftoff, ascent, and first stage recovery for Ares I. The flight test data from Ares I-X will be used to improve the Ares I design before its critical design review in 2011 - the final review before manufacturing of the flight vehicle begins.

\section{Vehicle Elements \& Mission Objectives}

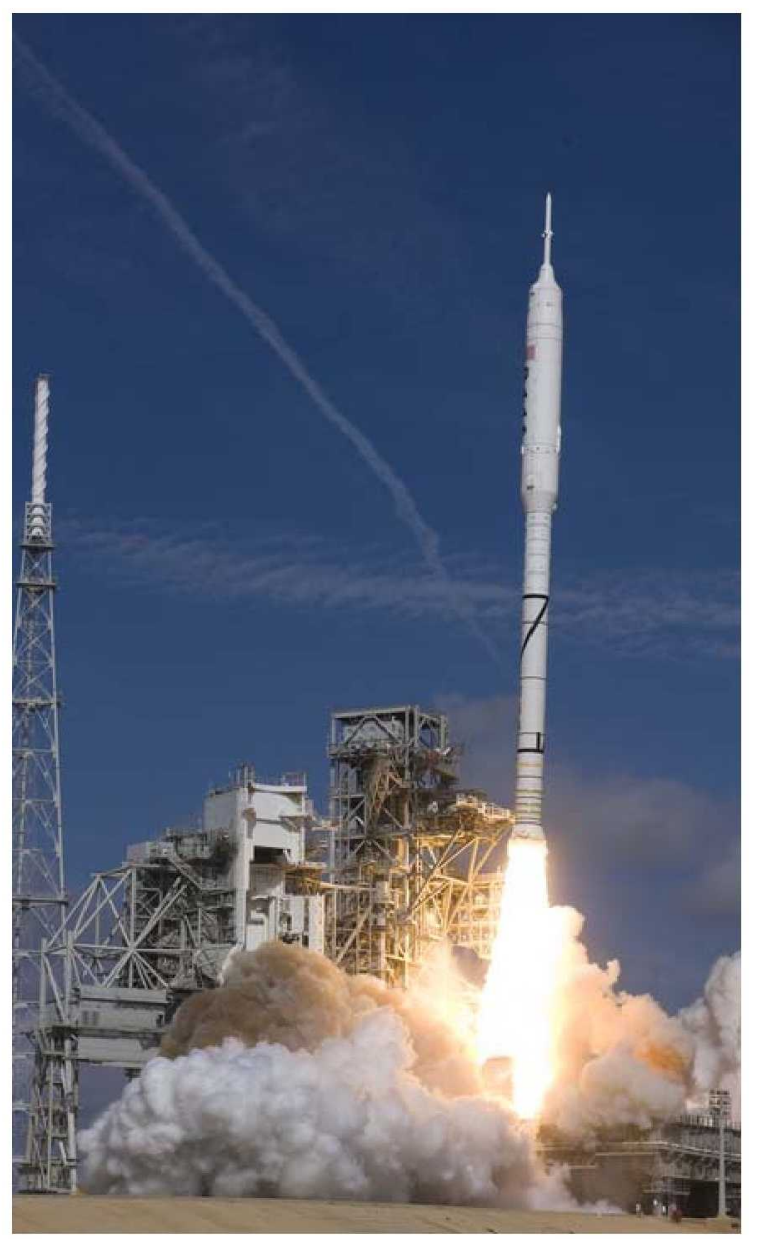

The Ares I-X flight test vehicle (FTV, Figure 1) was not designed to be a full-up space launch vehicle, but rather a development test article for evaluating how the rocket performs from liftoff through first stage separation. The rocket consisted of a four-segment solid rocket booster (SRB) from the Space Shuttle inventory with new forward structures, an active roll control system (RoCS), Atlas $\mathrm{V}$ avionics, and outer mold line simulators for the upper stage, Orion crew module, and launch abort system.

The flight and ground elements were developed, built, and integrated at multiple NASA centers, with the first stage managed at MSFC in Alabama and fabricated at ATK in Utah; the avionics systems managed by MSFC and built and tested by a combined Jacobs Engineering/Lockheed Martin team in Alabama and Colorado; the roll control engines managed at MSFC and reconfigured for Ares I-X at Teledyne Brown Engineering in Huntsville, AL; the upper stage simulator built at Glenn Research Center (GRC) in Ohio; the crew module/launch abort system (CM/LAS) simulator built and systems engineering and integration (SE\&I) function performed at Langley Research Center (LaRC) in Virginia; and the ground systems and operations performed at Kennedy Space Center (KSC) in Florida.

Figure 1. Ares I-X performs a "fly-away" maneuver just after liftoff from Kennedy Space Center's Launch Complex 39B.

This part-active, part-simulator vehicle was designed to achieve — and met —all of the following objectives:

- Demonstrate control of a dynamically similar, integrated Ares I/Orion, using Ares I relevant ascent control algorithms

- Perform an in-flight separation/staging event between a Ares I-similar first stage and a representative upper stage

- Demonstrate assembly and recovery of a new Ares I-like first stage element at KSC 
- Demonstrate first stage separation sequencing, and quantify first stage atmospheric entry dynamics, and parachute performance

- Characterize magnitude of integrated vehicle roll torque throughout first stage flight

\section{Operational Lessons Learned}

Operational lessons from Ares I-X will be especially important for NASA as the agency retires the Space Shuttle and transitions to the Constellation Program, which is designed to explore beyond LEO, but also be less labor-intensive during stacking and pad operations. The Ares I-X mission had a "lean" team, comprising approximately 700 civil servant employees over the life of the project compared to the thousands involved in Shuttle and Apollo missions. While missions to and beyond low-Earth orbit obviously will require additional personnel, this lean approach will serve as a model for future Constellation missions. The effort to design, build, transport, assemble, and launch Ares I-X provides an opportunity for a new generation of engineers and operations staff to work with a new launch vehicle.

\section{Logistics and Infrastructure}

Several special arrangements had to be made to transport all of the vehicle elements to KSC. Additionally, vehicle stacking and launch infrastructure had to be modified at KSC's Vehicle Assembly Building (VAB) and Launch Complex (LC) 39B to accommodate this new rocket.

Because the Ares I-X flight test vehicle (FTV) was built at multiple sites across the nation, it required multiple means of transportation to reach KSC. The first stage motor segments traveled from the ATK plant in Utah to Florida by rail, using methods and equipment already set up to support the Space Shuttle. The new forward structures arrived from an ATK subcontractor via truck from Indiana. The CM/LAS simulator was flown to KSC on a U.S. Air Force C-5 cargo transport.

The upper stage simulator (USS) required the most complex transportation logistics, as Glenn Research Center (GRC) in Ohio traditionally has not been part of NASA's launch vehicle infrastructure (Figure 2). The USS had to be broken up into 11 cylindrical sections known as "tuna cans" no taller than 9.5 feet ( 2.9 meters) to ensure that they could fit under bridges when transported by truck via interstate highways and under bridges when transported by commercial barge on the Ohio and Mississippi Rivers. The USS segments also included interior platforms and ladders to give ground operations staff access to interior sections above the height of the Shuttle-era fixed service structure (FSS) at Launch Complex 39B.
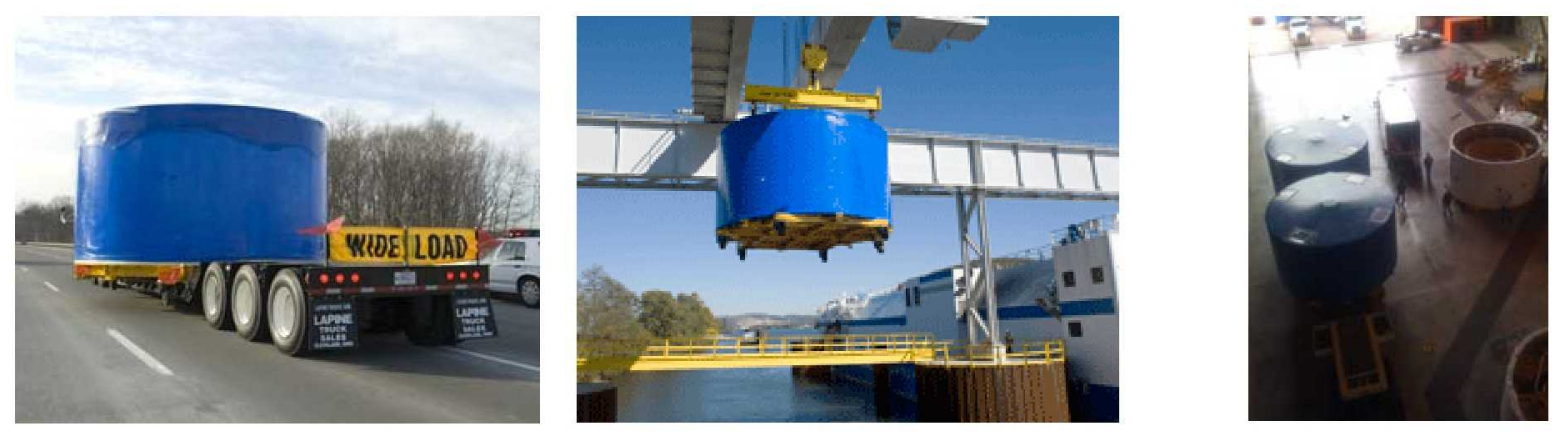

Figure 2. Transport sequence for the Ares I-X Upper Stage Simulator: tractor-trailer to the Ohio River, barge transport on the Delta Mariner to KSC, tractor-trailer from port to the VAB. 

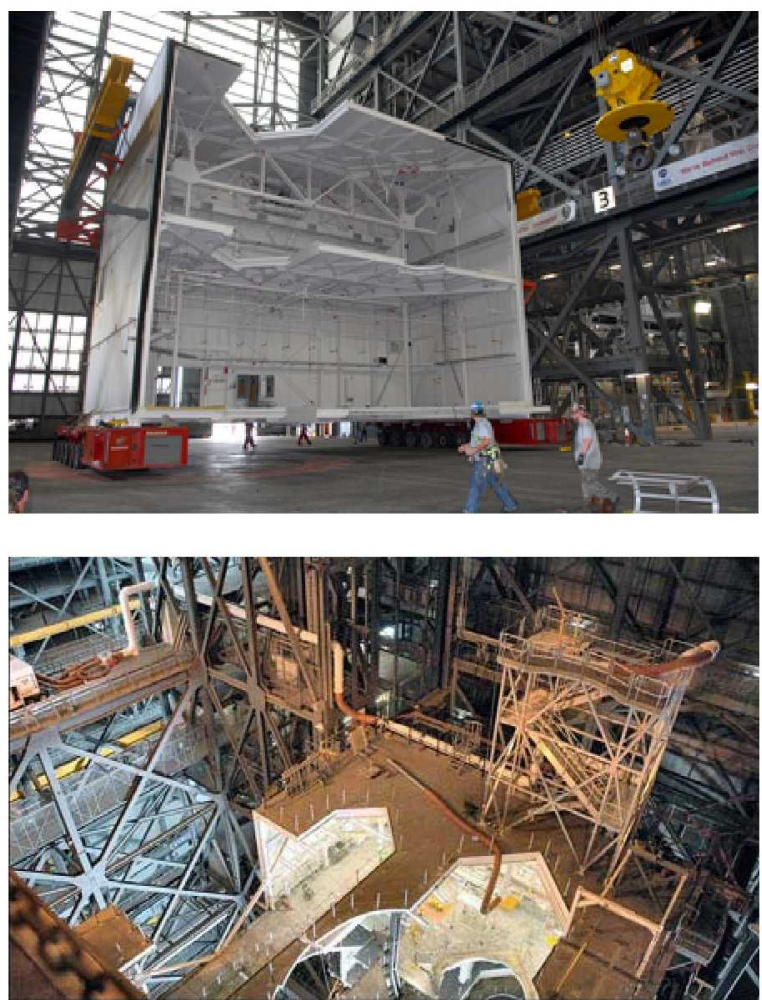

Figure 3. Platform $\mathrm{C}$ was removed from the VAB's High Bay 3 (top) and other platforms were added (bottom) to give ground operations staff access to the Ares I-X interstage segment.

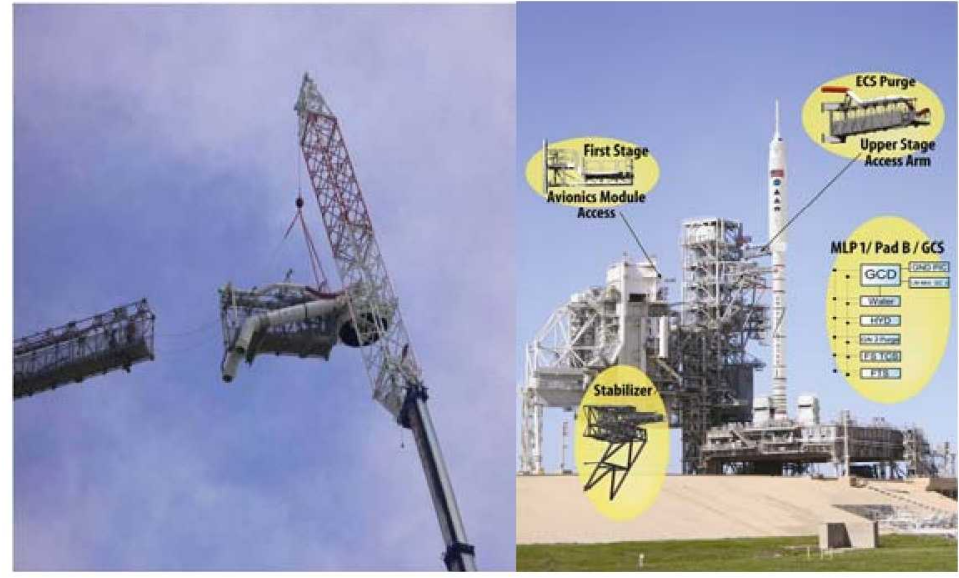

Figure 4. Gaseous oxygen arm being removed (left) and artist's concept (right) depicting hardware added to LC 39B for Ares I$\mathbf{X}$.
In the VAB, several platforms and other structures designed for the Space Shuttle's configuration had to be removed to accommodate the much taller, in-line design of Ares I-X, while other platforms and environmental control systems had to be installed to meet flight test needs (Figure 3).

Vehicle preparation activities resulted in lessons learned for ground operations personnel, including hardware deliveries, cable routing, transferred work and custodial paperwork.

Ares I-X also proved to be a resource challenge, as individuals and ground service equipment (GSE) supporting the mission also were required for Shuttle or Atlas V operations at LC 40/41 at Cape Canaveral Air Force Station. Conflicts over resources will continue to be a challenge for the agency in the next few years, especially if Ares flight tests continue while the Space Shuttle Program is extended.

At LC 39B, several Shuttle-specific access arms were removed (e.g. the gaseous oxygen "cap" usually attached to the top of the external tank) and others were added (the vehicle stabilization system, environmental control system, and access bridge for the first stage avionics module) to accommodate the Ares I-X FTV (Figure 4). However, this work was delayed by resource conflicts, including a launch-on-need backup mission for the Hubble Space Telescope servicing flight in August 2009. 


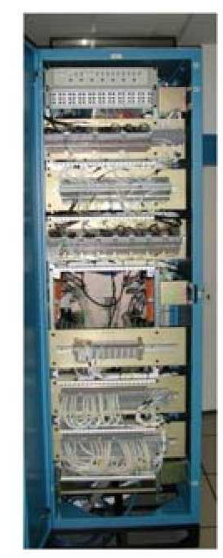

Figure 5. The GC3 rack installed in the Mobile Launcher Platform also is used to control Atlas V.
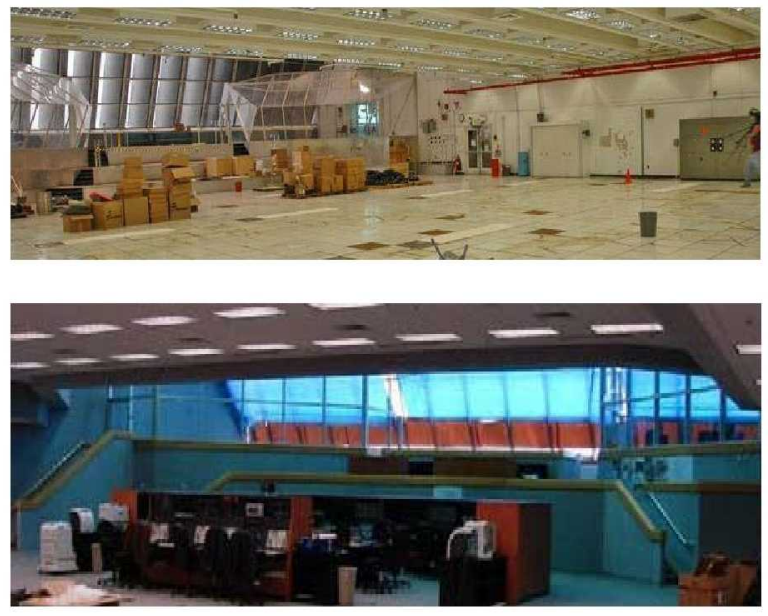

Figure 6. The VAB Launch Control Center's Firing Room 1, before (top) and after (bottom) refurbishment for Ares I-X.

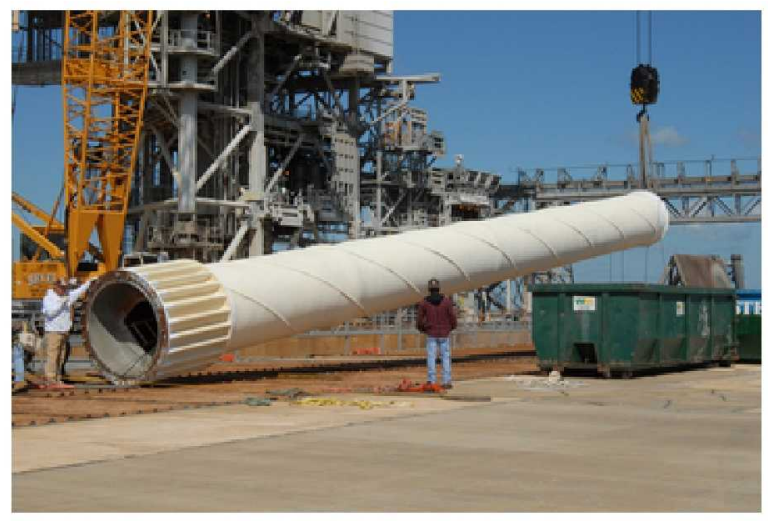

Ground command, control, and communication (GC3) hardware was incorporated into the Mobile Launcher Platform (MLP). The primary function of the GC3 unit, an Atlas V system provided by Lockheed Martin, was to provide control and data interfaces between the FTV and ground operations during countdown operations.

Perhaps the most dramatic change made to KSC's launch infrastructure was made to the VAB Launch Control Center's Firing Room 1. Originally used to launch the first Space Shuttle mission, Firing Room 1 received a complete refurbishment of its wiring, computer, console, and interior fixtures. The entire room was not needed, given the limited scope of Ares I-X, but once flight testing is completed, the room will be remade to support full Constellation Program missions to the International Space Station, the Moon, and beyond.

The lightning protection system at LC 39B was replaced by a trio of 600foot-tall towers connected by a catenary wire to account for the much greater height of the vehicle (Figure 7). These towers will be kept in place when the rest of the LC 39B service structure is dismantled to make way for purpose-built structures needed for the Constellation Program. 


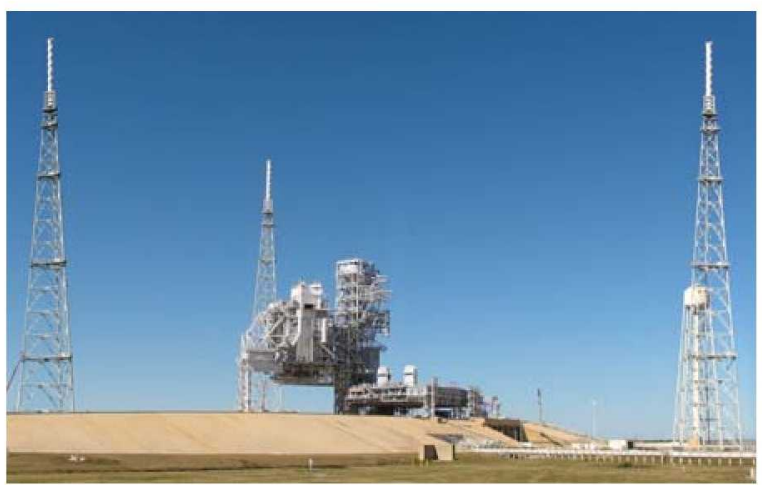

Figure 7. The single lightning mast atop the fixed service structure (FSS) at LC 39B (top) was replaced by a trio of towers (bottom).

Like Shuttle, Ares I-X was stacked on a MLP and rolled out to the pad on an Apollo-era crawlertransporter. Ares I-X was held in place by the four hold-down posts attached to the first stage aft skirt during rollout, and a new vehicle stabilization system (VSS) added to the vertical service structure kept the vehicle from swaying on the pad prior to launch. Both systems proved more than sturdy enough to keep the vehicle vertical. Wind-induced oscillations, even during winds up to $25 \mathrm{knots}$, did not exceed three inches over the entire length of the 327-foot rocket. The VSS itself, comprising commercial hydraulic struts, was a low-cost design choice made late in the project that proved as effective as a proposed support tower built atop the MLP. The use of commercial hardware saved the agency millions of dollars.

\section{Vehicle Stacking and Launch}

The stacking of Ares I-X went very smoothly, demonstrating the conscientious efforts by the Ares I$\mathrm{X}$ team to keep the vehicle's design and hardware fabrication integrated across multiple NASA centers. The vehicle segments, but also particularly the avionics hardware, fit and functioned together with minimal rework. Problems were solved by a dedicated trouble-shooting team established on-site at the $\mathrm{VAB}$, with a separate team established to address issues with the over 700 sensors comprising the developmental flight instrumentation (DFI).

One of the most surprising lessons learned during Ares I-X was the launch constraint imposed by triboelectrification, a static-generating condition created by flying through moisture-laden clouds that can interfere with radio signals to and from the vehicle. Triboelectrification can be mitigated most easily by encasing electronics in "Faraday cage" structures that insulate electronics from exterior sources of static and by covering the vehicle in non-static-producing paint. Late in the mission planning, there was some question about whether Ares I-X had paint which was not consistent with triboelectrification requirements on some of its exterior surfaces. Because the mitigation analysis was still in work as the launch day approached, the four-hour scheduled launch windows in October were constrained by the need for nearly cloud-free skies. Ares I-X finally launched on the second day's attempt after multiple windows failed to meet triboelectrification requirements. Future Ares vehicles will address this issue earlier in the requirements process.

Additional challenges to launch were created by difficulties removing a five-hole probe sensor cover prior to launch, commercial shipping entering the launch range, and the need to recheck the avionics systems after a thunderstorm the night after the first day's launch window. 


\section{Organizational Lessons Learned}

Lessons learned from Ares I-X will be shared with the Ares Projects through written and verbal reports and through integration of mission team members into the Project workforce.

As noted earlier, the flight and ground elements were developed, built, and integrated at multiple NASA centers, making for a complex technical and management environment. Because of this complexity and the likelihood that it will continue, Ares I-X was observed closely as a potential management model for future human spaceflight projects.

Originally multiple organizations were charged with responsibility for executing Ares I-X, including the Ares Projects Flight and Integrated Test Office (FITO) at MSFC, SE\&I at LaRC, and Ground Operations at KSC. The Ares I-X Mission Management Office (MMO) was established by the Constellation Program as a separate organization uniting these diverse entities to reduce red tape, overlapping/conflicting lines of authority, and numbers of review boards required to approve engineering changes. With the MMO established, mission goals, roles, and responsibilities were more clearly defined and progress became more rapid.

Over the course of test development, the MMO identified the following lessons learned as affecting mission success:

\section{Establish Clear Mission Objectives}

In the case of Ares I-X, these objectives supported early definition of the flight and ground hardware configurations; helped define the organizational structure; supported a more rapid development timeline; and reduced continual assessment of mission objectives and requirements. As a result of establishing our mission objectives early and not allowing them to evolve or "creep," the team was able to stay on task and, for the most part, stay on schedule.

\section{Employ a Small and "Flat" Team Organization}

The smaller, leaner, and "flatter" (compared to the Shuttle or parent Ares) organization minimized decision times, encouraged communication among the various players, and enhanced a "sense of team." A small team provided almost a "skunk works"-like approach, where the MMO was able to pull talented people and dedicated people from across the agency. One thing that could have been done earlier and better was to co-locate key personnel in one location, but that option was not feasible. Instead, the team communicated daily via teleconferences, email, and in-person meetings. However, there were times when the smaller staff resulted in work overloading on particular individuals. The end result was that the small, flat team worked well for Ares I-X, but it might not work in other situations. Efforts will need to be made in the future to ensure that similar "lean" teams have contingency plans and backup resources to call upon to reduce workload on key personnel.

\section{Loads and Environments Development}

The estimated aerodynamic, thermal, acoustic, and other loads and environments affecting the FTV were analyzed right up to the end, as the computer models for the flight environments and the vehicle flying through them evolved. The models evolved as the team learned to refine which elements of their models were too conservative or not conservative enough. These loads analysis cycles caused a strain on the team and additional time pressure as the launch date approached. In the future, flight test teams will learn to expect loads and environments changes and plan accordingly. 


\section{Establish Clear Development Flight Instrumentation (DFI) Requirements}

When the engineers and scientists were originally asked what DFI sensors they needed or wanted on the FTV for an effective test, the total requested resulted in a list of over 5,000 sensors. Additionally, more time was spent discussing potential sensor removal (or better stated as "not installation") than the actual time installing the sensors. As a result of these situations, it became clear that working from the top down based on flight test objectives leads to a more appropriate sensor suite. The MMO leadership team came to realize that proposing a reduction to an approved sensor suite will most likely result in a lengthy discussion (controversy). The best way to handle issues of this sort is to establish a separate DFI Control Board.

It Takes a Lot of Effort to Change Very Strong Institutional and Programmatic Ways of Doing Business

While NASA is assumed by the public to be a single entity spread across multiple Centers, the fact remains that each of these Centers has its own special history, institutional culture, and set of practices that affect how business is done. For example, technical and procedural terminology is different between centers, and there are variations in practices and procedures for verification, integrated testing, engineering file formats, and review processes, which can impact the program. These inter-Center differences mean that future mission teams will need to establish review processes early to eliminate conflicting or overlapping engineering reviews. Another lesson learned while developing the avionics for Ares I-X was that contractor processes are different from, and in some cases more applicable to, the project at hand.

\section{Establish an Engineering Development Fixture (EDF) for CAD 3-D Models}

Early in the formation of the Ares I-X MMO, the team established a digital EDF that supported fit checks of interfaces and configuration changes/updates; enabled the team to move through the design process quickly while communicating at the design level between IPTs; and supported the engineering and independent review process used in detailed communication of the design. By establishing the requirement for an EDF early in the design process, the team was able to identify interferences early that saved schedule, cost, and rework. A CAD model delivery schedule and format specifications also were established as contractual requirements early in the flight test planning. One thing the Ares I-X team did not do was establish fixed standards for submitting engineering models. As a result, a great deal of time was spent converting file formats, which slowed our use of the EDF.

\section{Conclusion}

Ares I-X has provided NASA personnel with first-hand knowledge of how to develop, build, launch, and absorb the lessons from a new launch vehicle. This valuable experience will continue to provide dividends as the agency develops Ares I or another rocket to succeed the Space Shuttle. Hardware and formal processes can be transferred from one generation of engineers and operations personnel relatively easily. The more flight tests NASA personnel are able to perform in the coming years, the better prepared they will be to handle future challenges and emergencies when human beings once again explore beyond low-Earth orbit. 


\section{Nomenclature}

CAD Computer-Aided Design

CM Crew Module

DFI Developmental Flight Instrumentation

EDF Engineering Development Fixture

FTV Flight Test Vehicle

GC3 Ground Command, Control, and Communication

GRC Glenn Research Center

GSE Ground Service Equipment

ISS International Space Station

IV\&V Independent Validation and Verification

KSC Kennedy Space Center

LaRC Langley Research Center

LAS Launch Abort System

LC Launch Complex

LEO Low-Earth Orbit

MLP Mobile Launcher Platform

MMO Mission Management Office

MSFC Marshall Space Flight Center

RoCS Roll Control System

SE\&I Systems Engineering and Integration

SRB Solid Rocket Booster

USS Upper Stage Simulator

VAB Vehicle Assembly Building

VSS Vehicle Stabilization System 


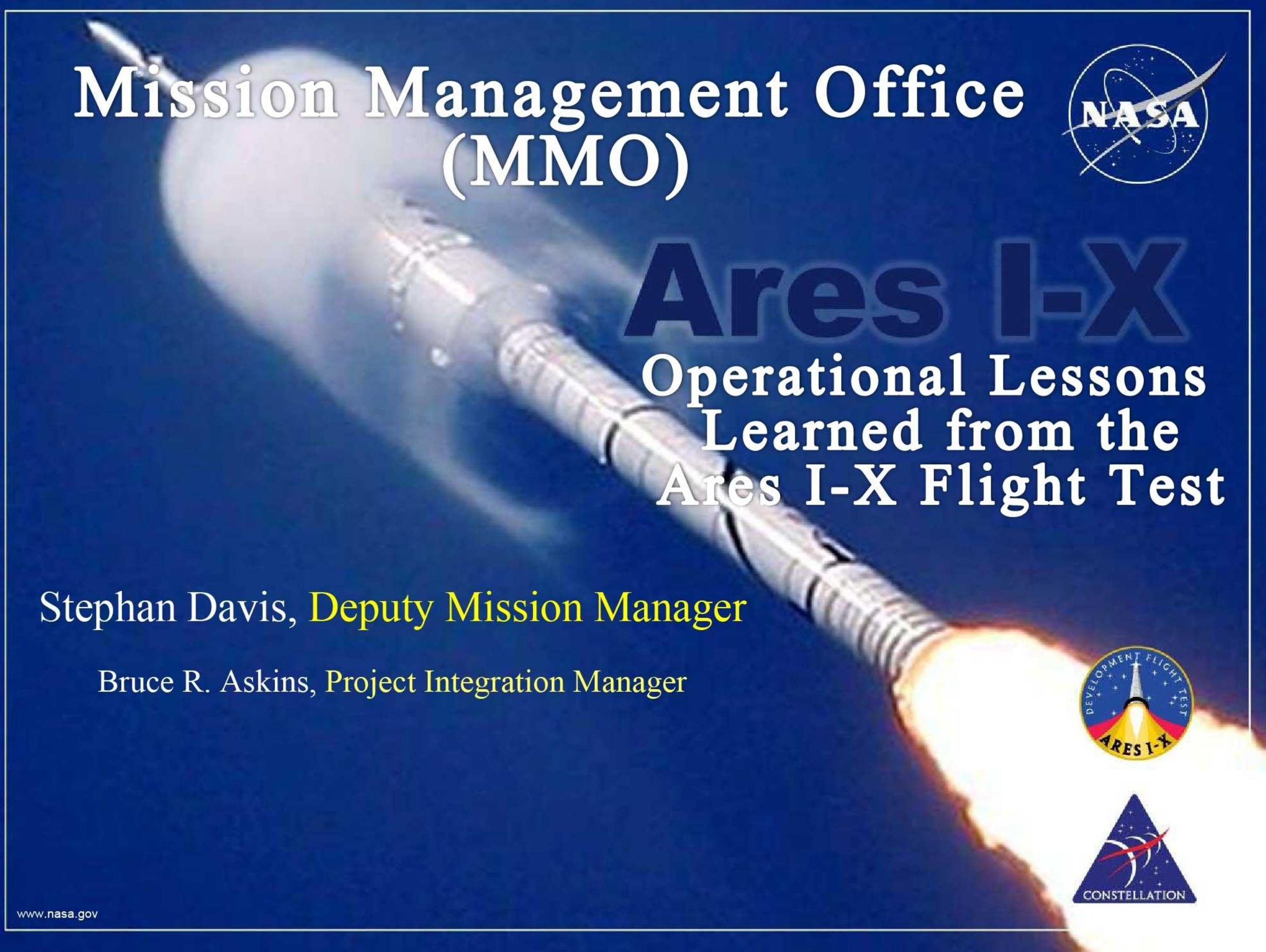




\section{Outline}

- Introduction to Ares I-X

- Mission Overview

- Hardware Overview

- Operational Lessons Learned

- Logistics and Infrastructure

- Vehicle Stacking and Launch

- Organizational Lessons Learned

- Summary 


\section{Ares I-X: The Basics (1 of 2)}

- Mission overview

- Uncrewed, suborbital development flight test

- Collected engineering data from launch to first stage recovery

- Support Ares I critical design review

- Mission rationale

- The Ares Projects reflect the Apollo method of "test as you fly" as well as current modeling practices until we are certain the rocket is safe enough to launch astronauts into space

\section{- Launch operations}

- Vehicle launched 11:30 a.m. Eastern Time, October 28, 2009, from Launch Complex 39B at Kennedy Space Center (KSC) 


\section{Ares I-X: The Basics (2 of 2)}

- Hardware overview

- Primary flight hardware consisted of a four-segment solid rocket booster from the Space Shuttle program

- Rocket controlled by Atlas $\mathrm{V}$ rocket avionics

- Status

- Mission successfully completed all primary mission objectives

- Onboard and telemetered data now being recovered and assessed

- First stage hardware being dismantled and examined 


\section{Vehicle Overview}

CM / LAS Simulator

\section{Upper Stage}

Simulator

First Stage

A

$\leftarrow$ - Interstage

Frustum and Avionics

\section{Launch Abort}

System Simulator

- Crew Module Simulator

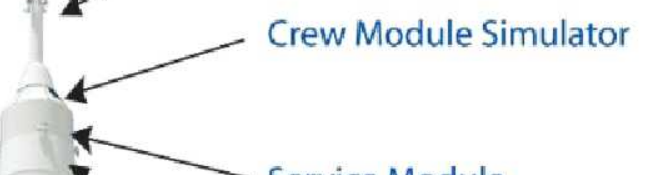

Service Module

Spacecraft Adapter

Roll Control System

Separation Plane

Forward skirt for packaging of recovery system

5th Segment Simulator

4- Segment Solid

Rocket Motor

(Space Shuttle)

Aft Skirt (Space Shuttle) with BTMs \& BDMs

Nozzle and thrust

vector control

(Space Shuttle)
- Combined proven space flight and simulation hardware

- Active Systems included:

- Four-segment solid rocket booster

- Atlas V-based avionics

- Roll control system

- Parachutes deceleration system

- Booster deceleration and tumble motors

- Developmental flight instrumentation

\section{- Simulator hardware}

- Upper stage

- Orion crew module

- Launch abort system

- Fifth segment of booster 


\section{Ares I-X Development Flight Test}

P2) Perform in-flight separation/staging event at $124 \mathrm{sec} \sim 130,000$ feet

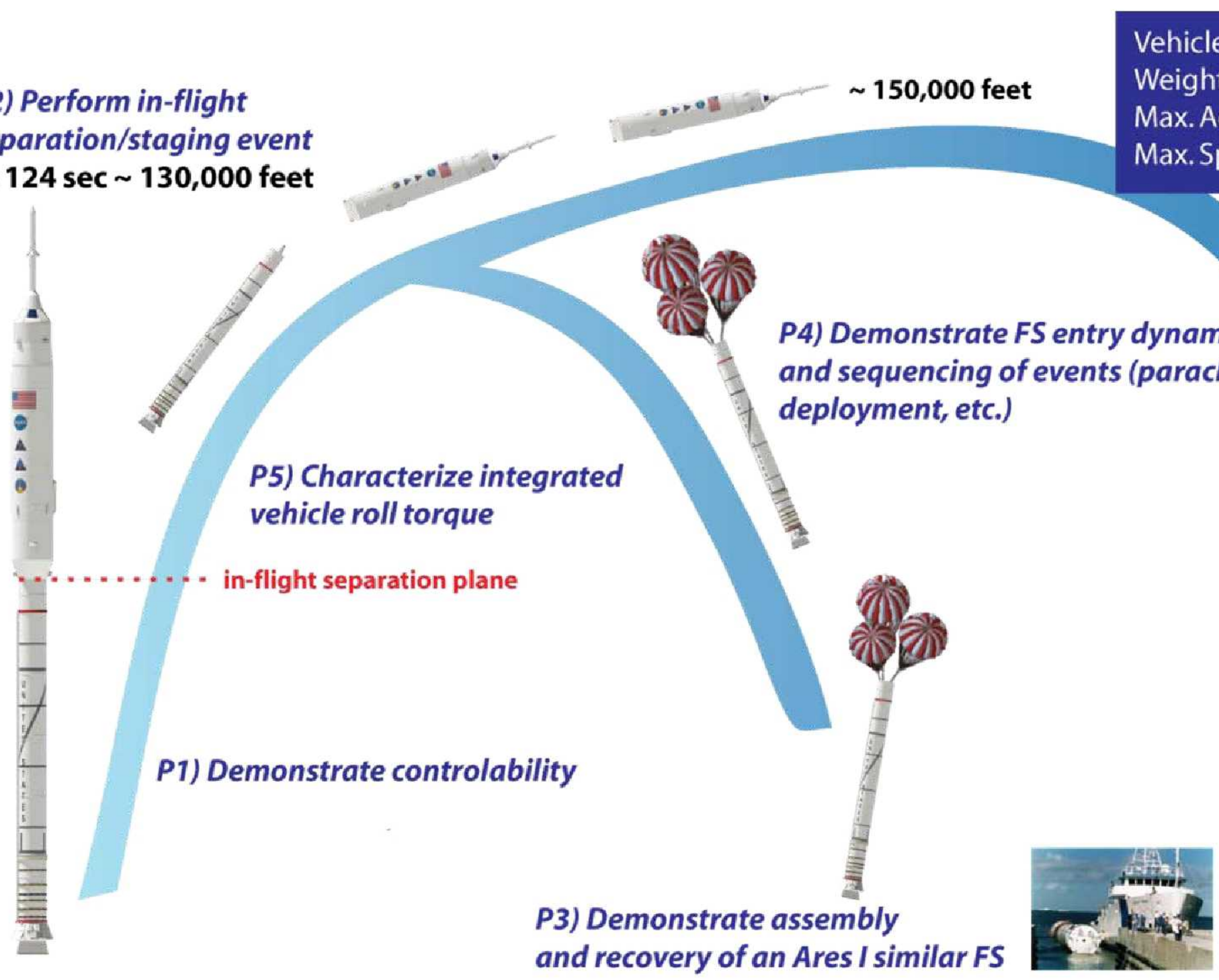

327 feet $1.8 \mathrm{M}-\mathrm{Ibm}$ $2.5 \mathrm{~g}$ 's Mach 4.7

Booster, parachutes and recovery 


\section{Ares I-X Flight Test Objectives}

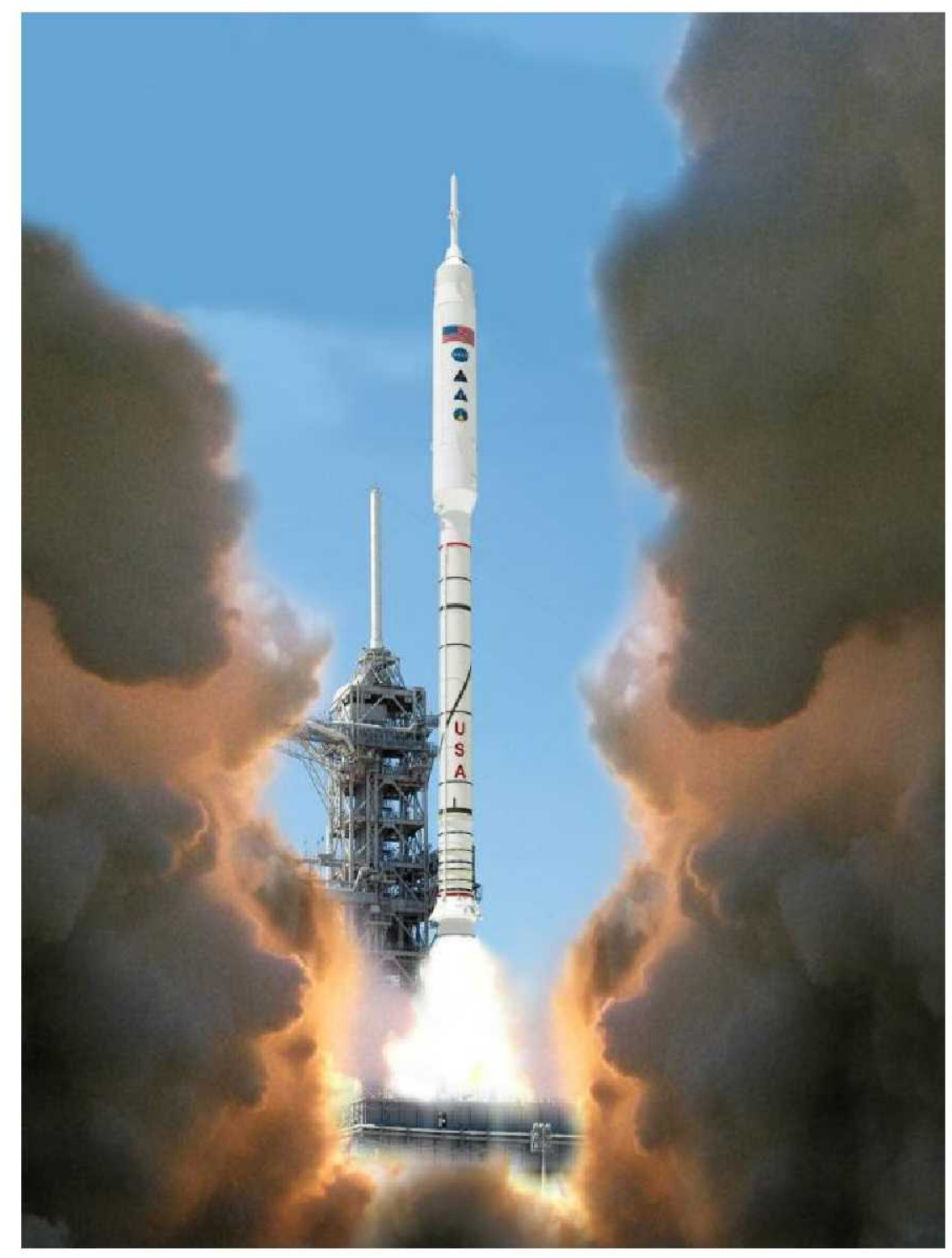

\section{Achieved ALL objectives:}

Demonstrated control of a dynamically similar, integrated Ares I/Orion, using

Ares I relevant ascent control algorithms

Performed an in-flight separation/staging event between a Ares I-similar First Stage and a representative Upper Stage

Demonstrated assembly and recovery of a new Ares I-like First Stage element at KSC

Demonstrated First Stage separation sequencing, and quantified First Stage atmospheric entry dynamics, and parachute performance

Characterized magnitude of integrated vehicle roll torque throughout First Stage flight 


\section{Operational Lessons Learned - Logistics and Infrastructure (1 of 2)}

- Transportation of vehicle elements

- Launch infrastructure modifications:

-KSC Vehicle Assembly Building

- Launch Complex 39B

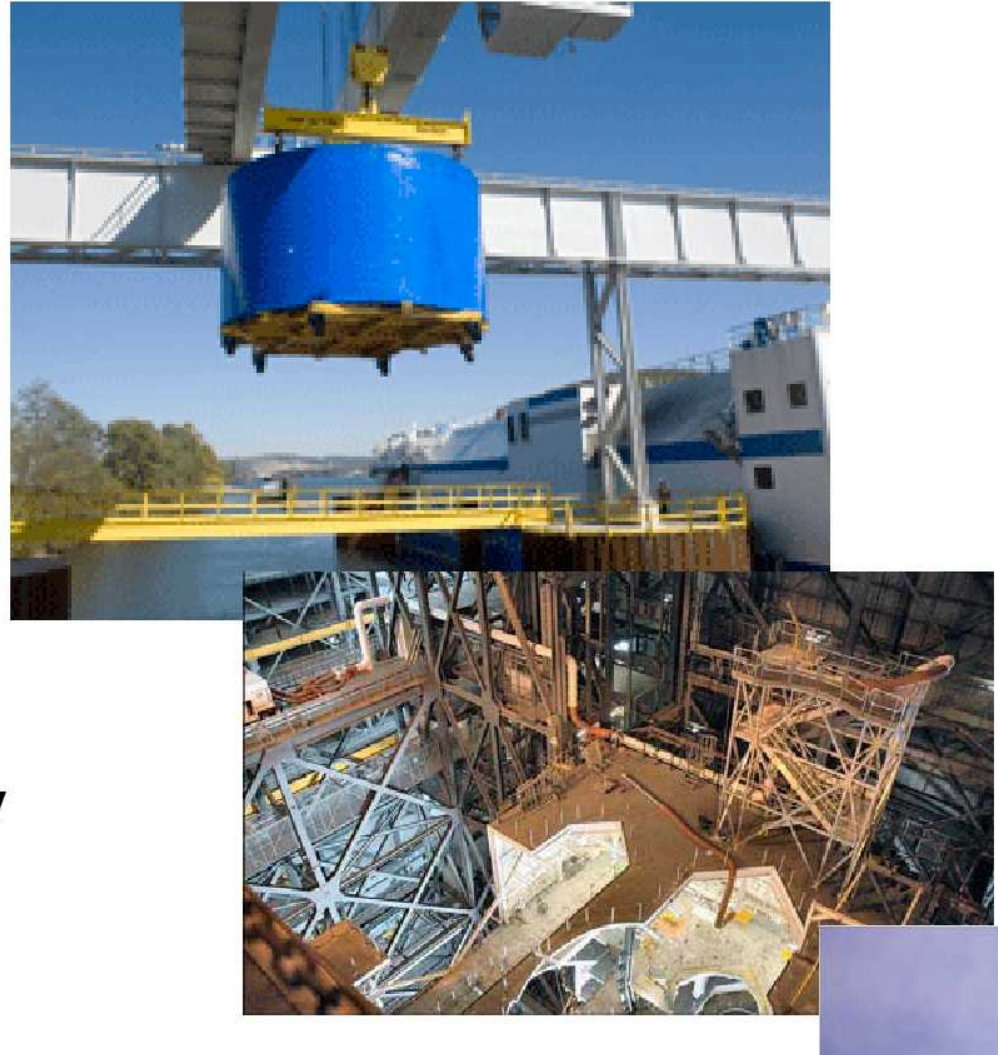

- Resource challenges 


\section{Operational Lessons Learned -}

Logistics and Infrastructure (2 of 2)

- Mobile Launcher Platform

- Launch Control
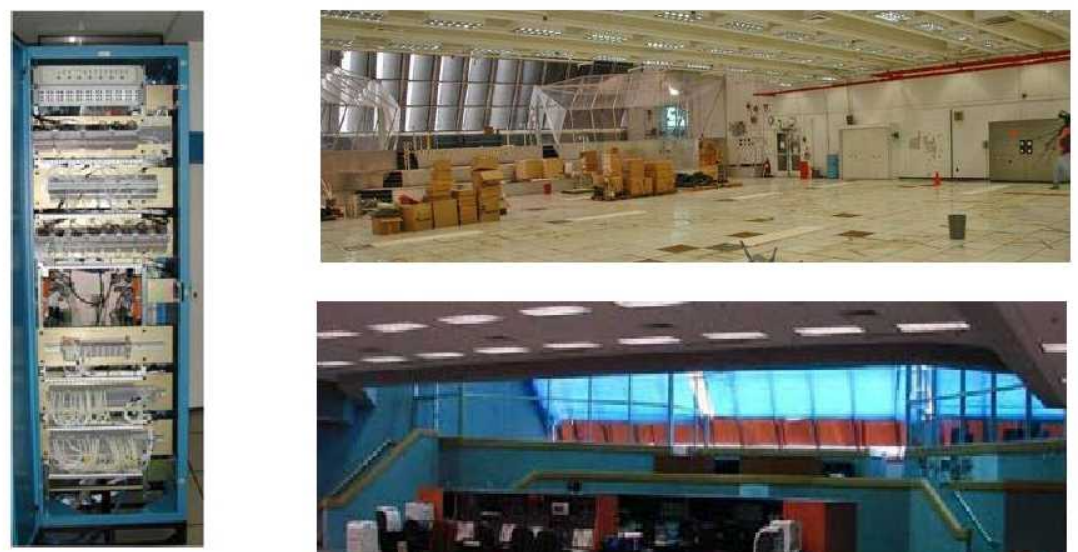
Center Firing Room

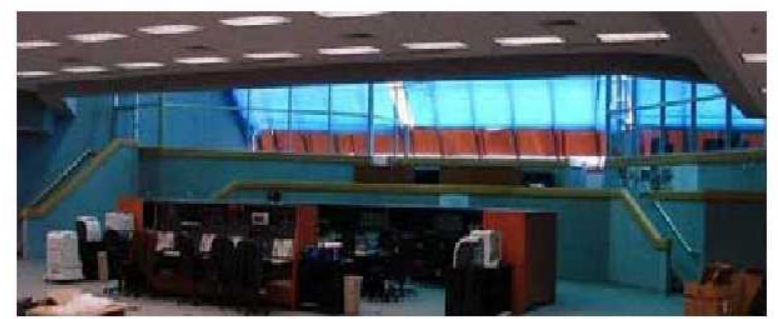

- Lightning Protection System

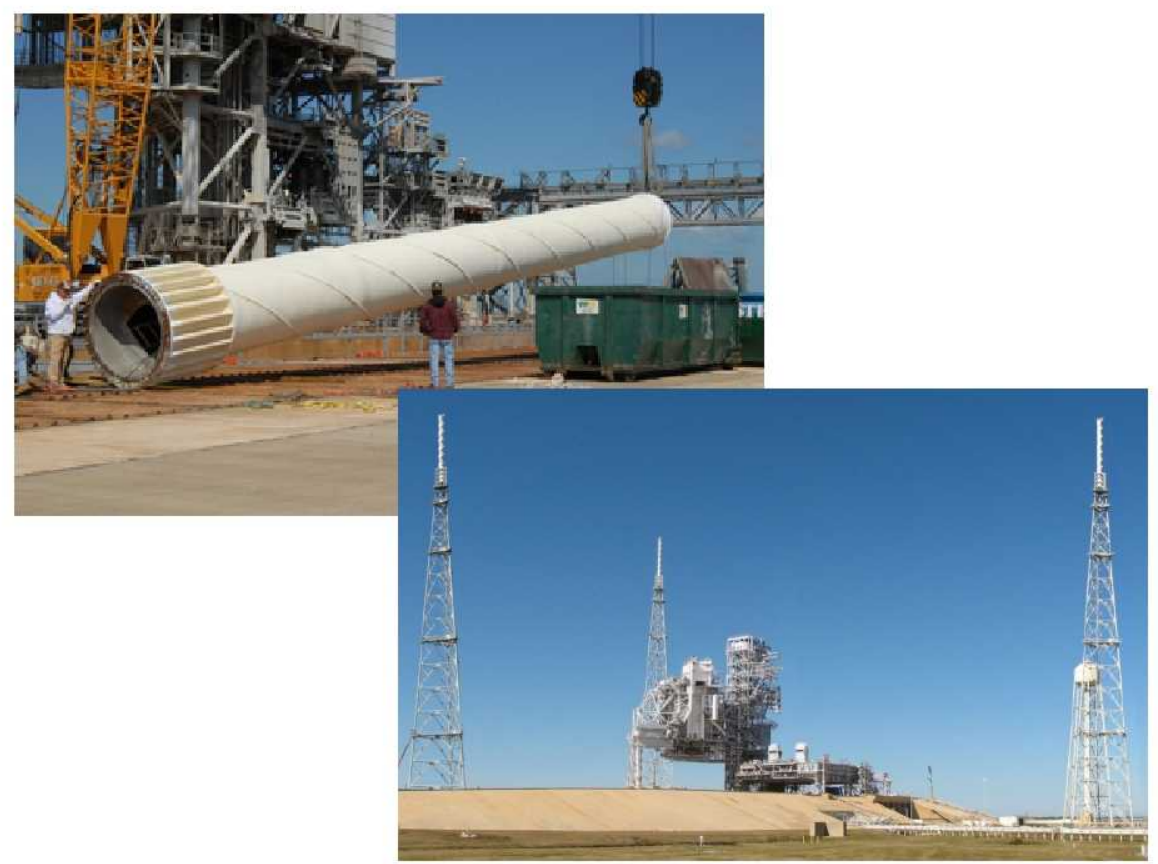


- Vehicle stacking

- Developmental Flight Instrumentation (DFI)

- Triboelectrification

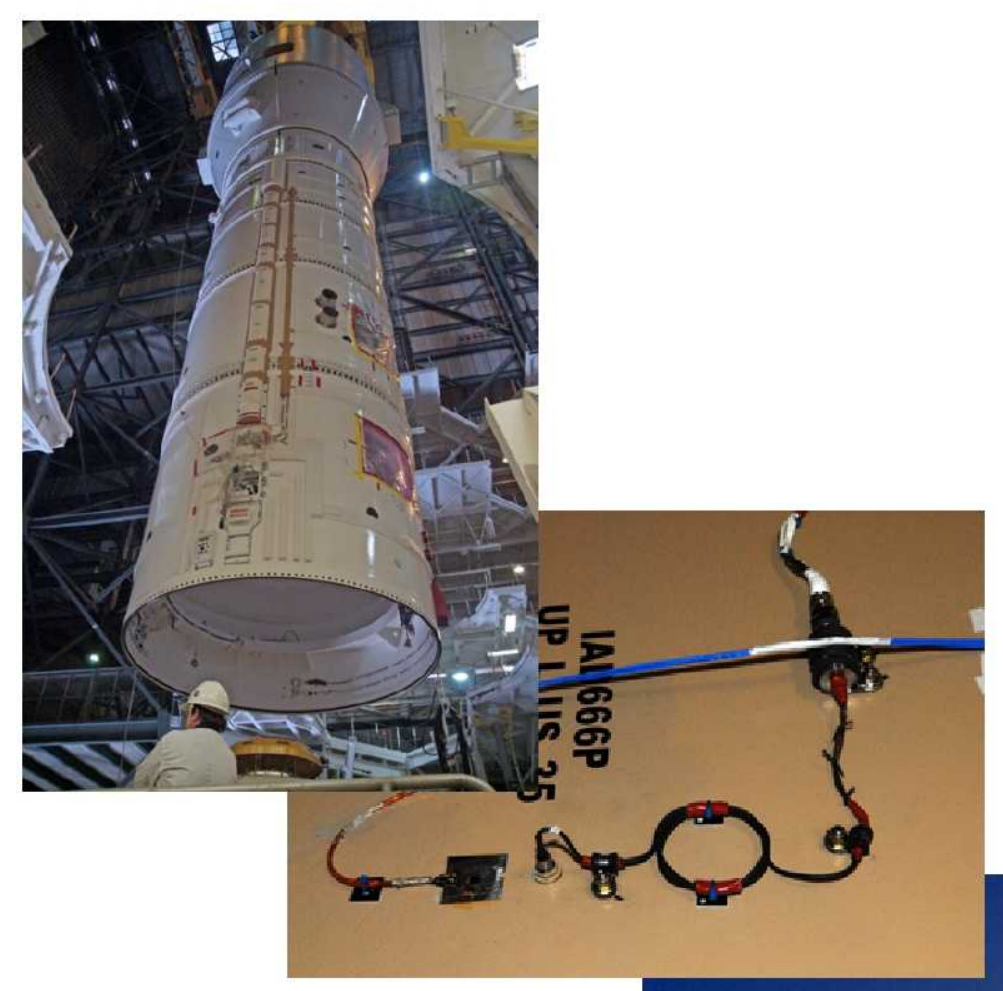




\section{Liftoff!}

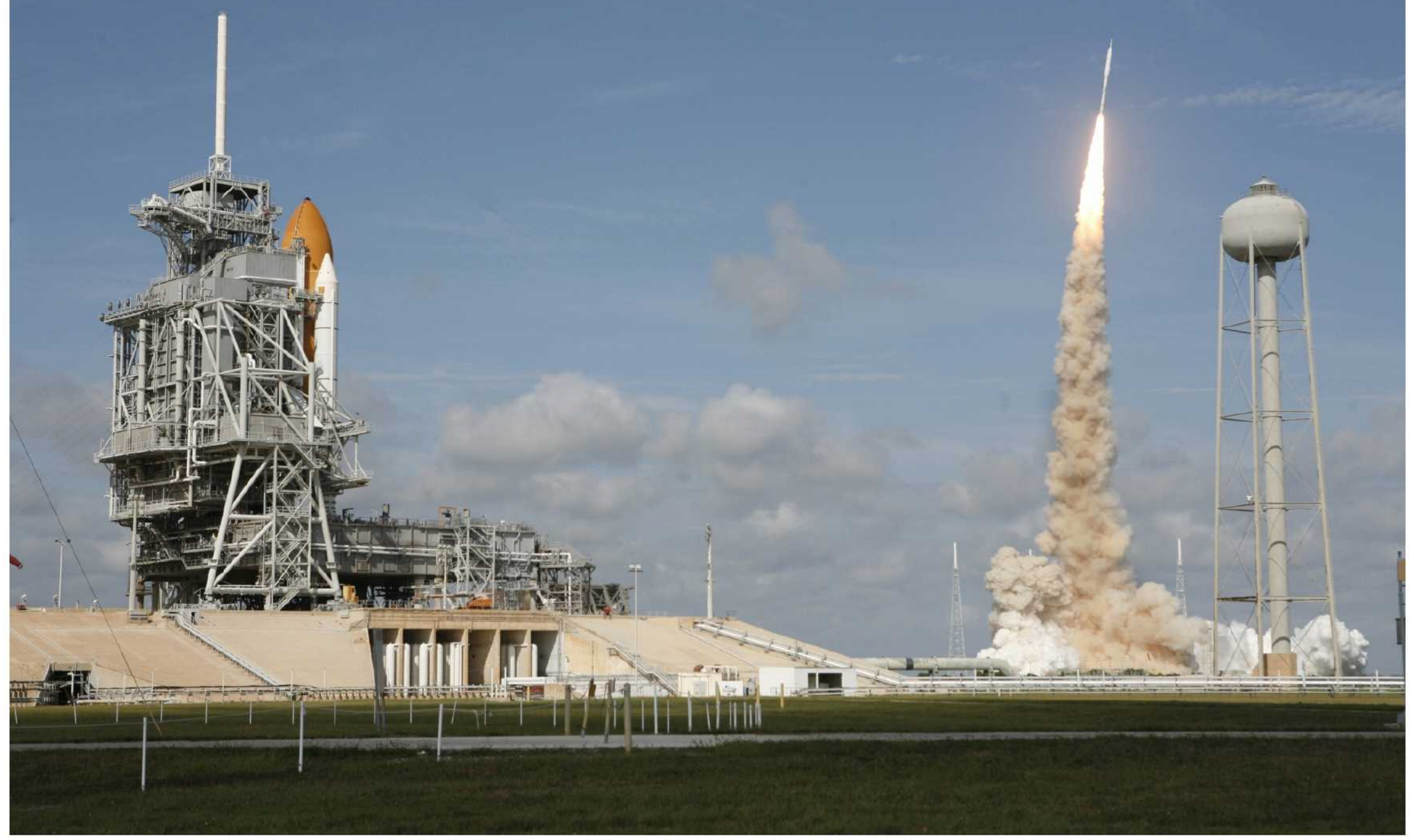




\section{Organizational Lessons Learned}

- Establish clear mission objectives

- Employ a small and "flat" team organization

- Expect loads and environments to evolve

- Establish clear DFI requirements

- It takes a lot of effort to change very strong institutional and programmatic ways of doing business

- Establish an engineering development fixture (EDF) for CAD 3-D models 


\section{Summary}

- Ares I-X has provided NASA personnel with first-hand knowledge of how to develop, build, and fly a new launch vehicle

- This valuable experience will provide dividends as the agency works with new launch vehicles

- Hardware and processes can be transferred from one generation of engineers and operations personnel to the next

- The more flight tests NASA personnel are able to perform, the better prepared they will be to handle future challenges and emergencies

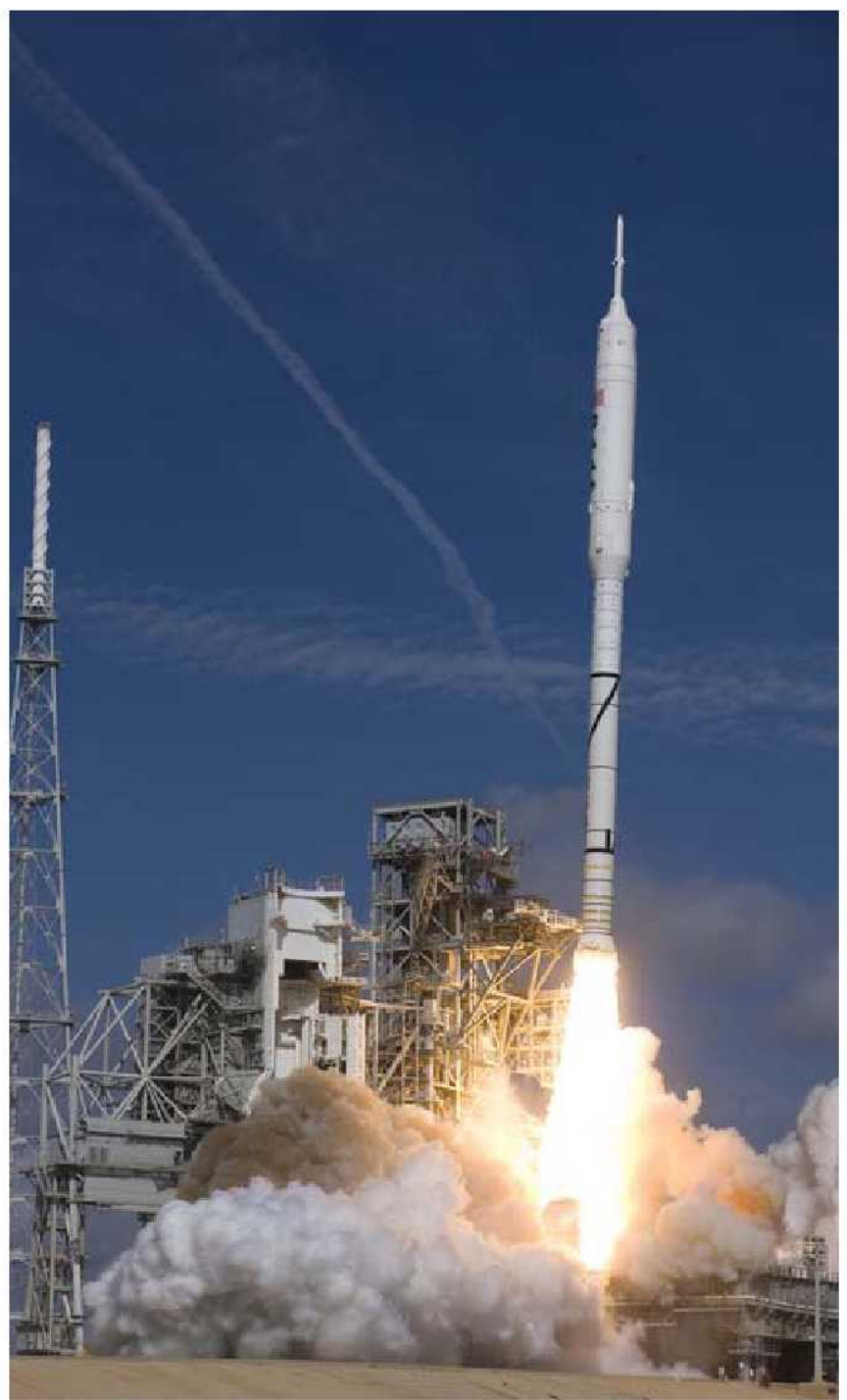




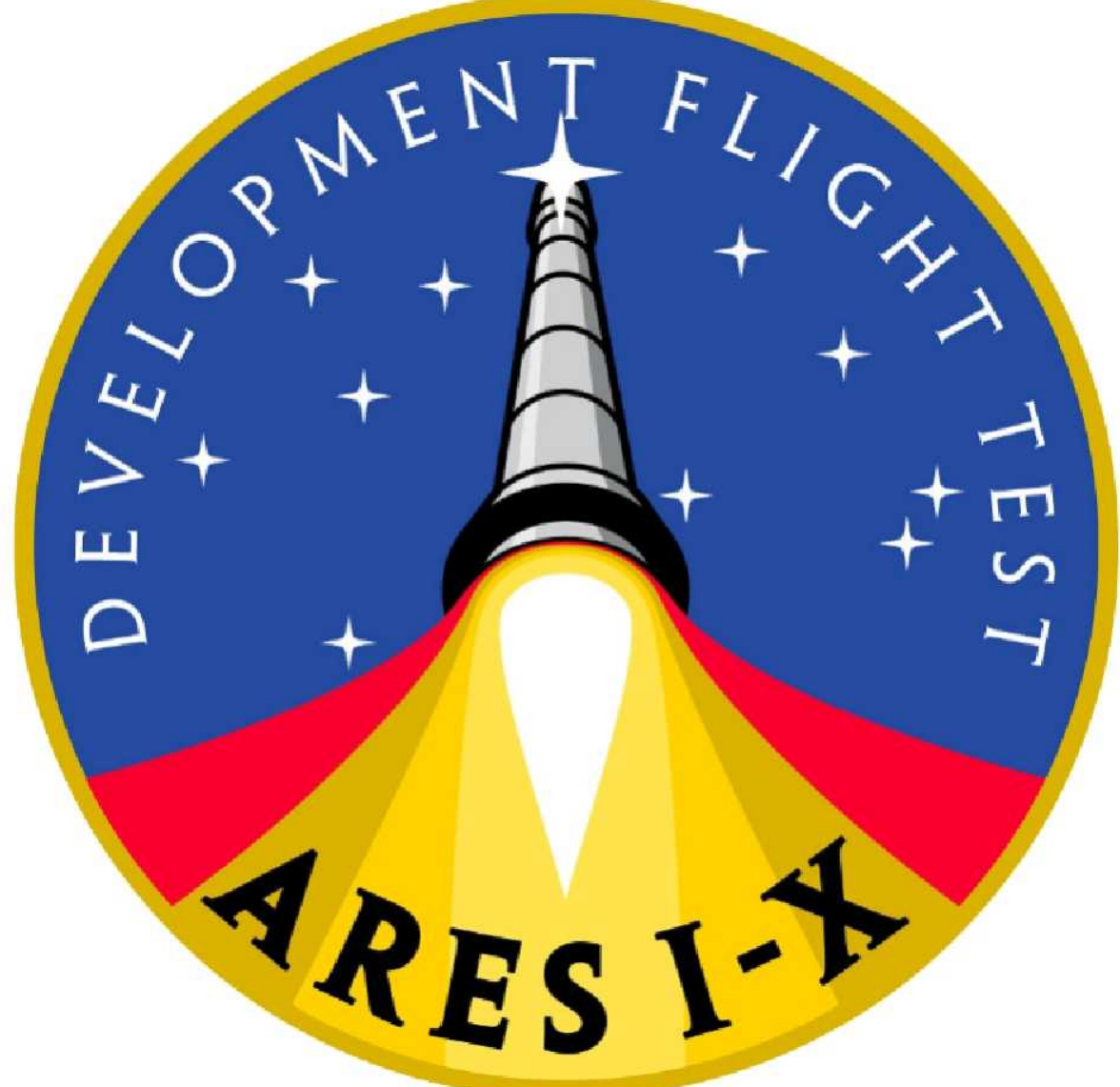

http://www.nasa.gov

http://www.nasa.gov/ares|X 